Recebido em: 20/08/2020. Aprovado em: 30/11/2020.

Processo de Avaliação: Double Blind Review - SEER/OJS

e-ISSN: 2359-5876

\title{
A controlabilidade (SCG) como propulsora do alinhamento entre o comportamento planejado e cenário ético-organizacionais
}

\author{
Delci Grapegia Dal Vesco ${ }^{1}$ (D) \\ Ketlyn da Silva Pasquali ${ }^{2}$
}

\section{Resumo}

A contabilidade sustenta-se em meio às influências de aspectos econômicos, políticos, culturais e históricos; dessa forma, essa ciência pode contribuir, por meio de controles gerenciais, a fim de conduzi-los a uma conduta ética e identificar aspectos associados a questões comportamentais, haja visto o sistema de controle gerencial relacionar-se às ações comportamentais dos indivíduos, direcionando-os ao cumprimento dos objetivos da instituição. Nessa perspectiva, esse estudo teve por objetivo discutir a validação do instrumento de pesquisa possível de captar a controlabilidade (SCG) como propulsora do alinhamento entre o comportamento planejado e cenário ético-organizacionais. Para o alcance do objetivo, discutiu-se a teoria e utilizou-se da metodologia de pesquisa descritivoexploratória, quantitativa e transversal. Recorreu-se a um levantamento por meio da aplicabilidade de um instrumento submetido à validade de conteúdo, com o crivo de etapas que consistiram desde análise critica por especialistas até a realização e adequação de pré-testes até o instrumento e o desenho teórico mostrar-se conceitualmente adequado e compreensível aos sujeitos. Foi aplicado em duas etapas a 23 sujeitos em níveis de escolaridade distintos para a avaliação preliminar da consistência interna. Após a validade conceitual fez a validação do desenho teórico por meio da determinação da confiabilidade composta que avaliou a consistência interna, a confiabilidade do indicador individual e a variância média extraída (AVE) que verificou a validade convergente e o critério de Fornell-Larcker foi utilizado para avaliar a validade discriminante, isso permitiu determinar a qualidade da mensuração do modelo. Os resultados indicam que o modelo é capaz de representar e captar a qualidade do modelo de pesquisa. Essa pesquisa poderá contribuir para estudos na linha de pesquisa em ética organizacional e sistemas de controles gerenciais. Para futuras pesquisas recomenda-se a implementação do modelo conceitual para a validação das hipóteses. A pesquisa contribui teórica, empírica e socialmente. Em destaque a contribuição de forma empírica pela proposição de cenários projetistas (simuladores de uma situação hipotética) ético-organizacionais a fim de apresentar aos participantes cenários cuidadosamente construídos e realistas para avaliar as intenções, atitudes e comportamentos, aumentando assim o realismo instrumental, e por neutralizar a percepção pessoal do respondente ao avaliar SCG e ética restrito a sua base comportamental.

Palavras-chave: Comportamento Planejado; Cenário ético-organizacional; Controlabilidade. Validade de instrumento de pesquisa.

Cite as: (APA) Dal Vesco, D. G., \& Pasquali, K. S. A controlabilidade (SCG) como propulsora do alinhamento entre o comportamento planejado e cenário ético-organizacionais. Revista Competitividade e Sustentabilidade, 7(3), 722-744.

\footnotetext{
${ }^{1}$ Doutora em Contabilidade pela Fundação Universidade Regional de Blumenau. Professora do Programa de PósGraduação Stricto Sensu em Contabilidade da Universidade Estadual do Oeste do Paraná - UNIOESTE. Brasil.

E-mail: delcigrape@gmail.com

2 Mestre em Contabilidade pela Universidade Estadual do Oeste do Paraná - Unioeste. Brasil. E-mail: 


\section{INTRODUÇÃO}

O tema em estudo versa sobre sistemas de controle gerencial e as intenções éticas dos profissionais contábeis. Sendo assim, a fim de gerir, monitorar e moderar esse comportamento, as empresas investem em sistemas de controle gerencial (SCG), os quais, entre outras coisas, determinam responsabilidades e recompensas para os funcionários (Oyadomari, Cardoso, Silva \& Perez, 2010; Lucena, Melo, Lustosa \& Silva, 2015) ou seja, aqui nessa discussão exercem a controlabilidade.

Além disso, a discussão da ética organizacional também tem sido evidenciada, visto que pode influenciar em atitudes e comportamentos relacionados à essência ética de uma organização (Treviño, Weaver \& Reynolds, 2006).

Moral e ética difundiram-se na sociedade e, muitas vezes, seus significados se confundem. A etimológia do termo moral, oriundo do latim, e ética, proveniente do grego, define "moral" como "costume" e "ética" sendo "caráter", de modo que ambos estabelecem análise comportamental. No entanto, pode-se dizer que moral é intrínseco ao ser humano; já ética é relativa, podendo ser moldada de acordo com princípios e valores sociais.

Conforme Schumann (2001), os princípios morais possuem a finalidade de guiar julgamentos morais, os quais se fragmentam em situações consideradas éticas ou antiéticas. Assim, o comportamento ético é um comportamento individual, sujeito ao arbitramento de adequação às normas de aceitação social de conduta (Treviño et al., 2006), de maneira que a idiossincrasia ética está, também, subordinada aos contextos circunstanciais daquele determinado momento em que o indivíduo ou a sociedade se encontra.

Dessa forma, as mudanças oriundas do avanço da tecnologia e o processo de globalização são influências importantes no modo de viver dos seres humanos e que se refletem no comportamento do indivíduo pós-moderno. Verifica-se, então, um aumento da violência, do egoísmo, da individualidade, concordando-se com Bauman (2000) quando afirma que as relações humanas na pós-modernidade se tornaram fluídas, líquidas, distantes, condicionando-as a uma perda de valores morais.

Essa perda de valores tem se refletido no meio empresarial, haja vista os casos de imoralidade contábil na Enron (2002), WorldCom (2002), Xerox (2002), Master Blenders (Café Pilão, 2012) e Petrobrás (2015), proporcionando a reflexão sobre a ética profissional.

Assim, conforme Sá (2000), independente do cargo ocupado, nas organizações o agir ético é essencial, exigindo preparo do funcionário para tomar decisões perante situações que tendem a surgir. Por isso, defendem Sembay, Ribas, Camargo e Maçaneiro (2014) que a ética está presente em todas as áreas e estabelece princípios que norteiam atitudes coerentes a serem seguidas em cada profissão.

Os fatores que podem afetar o comportamento ético dos gestores e funcionários em uma organização, consistem desde fatores pessoais, relatados por Bandura (1990), como aqueles que direcionam o indivíduo a esse desengajamento moral: a justificação moral, a linguagem eufemística e a comparação vantajosa; até fatores sociais que partem do pressuposto de que as crenças éticas independem das considerações econômicas. Todavia, Blanthorne e Kaplan (2008) entendem que as pessoas com mais oportunidades tendem a ser mais antiéticas em relação às pessoas com menos oportunidades. É uma relação de dependência: os indivíduos constroem seus princípios sociais; esses, juntamente com a oportunidade, influenciam as crenças éticas, as quais, por conseguinte, intencionam o cumprimento ético.

Assim, faz-se necessária a busca pelo conhecimento e a explanação da teoria que 
defende a ética com cenários. Reidenbach \& Robin (1990) apresentam as diferentes maneiras de como os indivíduos combinam possibilidades filosóficas para explicar a verdade sobre a ética e procuram identificar e mensurar o grau do comportamento ético por meio da técnica de cenários.

Trabalhar com cenários éticos segundo Reidenback \& Robin (1990) pode levar o indivíduo a uma percepção ética baseada nas atitudes dos protagonistas em cada cenário apresentado. Cohen, Pant e Sharp (1993) também apresentam teorias relevantes do processo de juízo ético dentro de uma sociedade diversificada

Por conseguinte, a temática ética organizacional está alcançando relevância nas pesquisas contábeis, destacando-se Victor e Cullen (1988), Wimbush, Shepard e Markham (1997), Cruz, Shafer e Strawser (2000), Flynn (2001), Borges e Medeiros (2007), Almeida e Alves (2014), Lucena et al. (2015) e Pasquali e Dal Vesco (2016). Além desses estudos referente a ética contábil como principal dimensão a ser averiguada, Loch e Conger (1996), Gibson e Frakes (1997) e Buchan (2005), por meio da Teoria do Comportamento Planejado (TCP), realizaram estudos com o intuito de expandir a compreensão dos fatores que influenciam as intenções e os comportamentos éticos.

Para Ghillyer (2015), é compreensível que muitos observadores acreditem que o mundo dos negócios não tenha senso ético algum, tratando ética e negócios como um oximoro, ou seja, a combinação de dois termos contraditórios., Em se tratando de ambiente organizacional, a ética empresarial é fundamental para o processo de tomada de decisão, afinal, as organizações são estruturas sociais que orientam os comportamentos éticos dos seus trabalhadores (Victor \& Cullen, 1988). Destarte, considerando que uma instituição ética respeita a autonomia dos indivíduos (Andrade, 2009), esse trabalho se diferencia dos demais apresentados, pois defende-se a aplicabilidade da ética-organizacional por meio do alinhamento cenários ético-organizacionais.

Assim, o objetivo do estudo consiste em discutir a validação do instrumento de pesquisa possível de captar a controlabilidade (SCG) como propulsora do alinhamento entre o comportamento planejado e cenário ético-organizacionais.

Embora a literatura sobre os temas Ética e Sistema de Controle Gerencial aponte para as recorrentes pesquisas com instrumentos do tipo Survey em questionamentos objetivos e diretos sobre comportamentos problemáticos, a contribuição desse estudo é justamente coletar dados via instrumento de pesquisa por meio de cenários etico-organizacionais a fim de apresentar aos participantes cenários cuidadosamente construídos e realistas para avaliar as intenções, atitudes e comportamentos, aumentando assim o realismo instrumental. Portanto, o estudo contribui de forma empírica pela proposição de cenários projetistas (simuladores de uma situação hipotética) por neutralizar a percepção pessoal do respondente ao avaliar seu comportamento.

A pesquisa possui justificativa, no que se refere ao campo da ética profissional nas empresas, para a interação das relações comportamentais nas práticas administrativas empresariais; e para fins instrumentais justifica-se por discutir um instrumento de pesquisa, em ética - organizacional e a controlabilidade, a partir de um conjunto de oito cenários ético simulados para representar o ambiente ético organizacional; e, ainda, a precisão de um avanço nas pesquisas em contabilidade desenvolvidas com a finalidade de compreender 0 comportamento humano.

Por fim, no que se refere ao campo da ética profissional nas empresas, a pesquisa contribui para a interação das relações comportamentais nas práticas administrativas das empresas, pois os laços econômicos frequentemente resultam em intenções 
comportamentais, as quais impactam no processo de tomada de decisão ao nível corporativo, conforme concepção introduzida por Ajzen (2002).

\section{2 - Comportamento Planejado, Controlabilidade (SCG) e Cenário Ético-Organizacionais}

Em se tratando de TCP, o comportamento passado não é uma medida de hábito, mas sim um reflexo de todos os fatores que irão determinar a intenção comportamental e, consequentemente, o comportamento futuro (relação entre intenção e ação) (Ajzen, 1991).

Ademais, a regra geral da TCP define que, quanto mais favorável a atitude e norma subjetiva, e quanto maior o controle percebido, mais forte é a intenção do indivíduo de realizar o comportamento em questão (Ajzen, 1985). Ou seja, as pessoas performam suas intenções de comportamento diante da oportunidade apresentada, em que a intenção é assumida como sendo a precedente imediata do comportamento.

Nesse sentido, a TCP revela-se como fiel em cumprir o objetivo de investigar o comportamento humano (Ajzen, 1991) lidando com os antecedentes das atitudes comportamentais, normas subjetivas e controle percebido, os quais determinam a relação intenção e ação.

Em uma visão mais contábil, Potrich et al. (2015) desenvolveram um modelo capaz de identificar a alfabetização financeira dos indivíduos, por meio de variáveis socioeconômicas e demográficas. Assim, a TCP foi empregada para explicar que as atitudes financeiras são estabelecidas pelas crenças econômicas e não econômicas e são um fator-chave no processo de tomada de decisão pessoal.

Ainda, nota-se que, de modo generalizado, as pesquisas apresentam como metodologia o estudo por meio de levantamento (ou survey). Caro et al. (2011) aplicaram equações estruturais em sua pesquisa e Potrich et al. (2015) trabalharam com modelo econométrico. Assim, os estudos foram realizados por meio de questionários com amostras consideráveis, enquadrando-se em pesquisas quantitativas (Ruiz et al., 2011; Caro et al., 2011; Potrich et al., 2015), revelando a falta de estudos qualitativos relacionados à TCP, os quais podem proporcionar uma compreensão mais abrangente da dinâmica de diferentes grupos humanos.

Destarte, fica evidente que a TCP é utilizada para averiguações comportamentais e, ainda, para predizer e explicar o comportamento em áreas divergentes (Estramiana \& Garrido, 2003), sendo uma teoria adaptável a diferentes contextos.

Já no que se refere a ética Sapiro (1993) esmiuçou a relevância ética com a inteligência empresarial e verificou que os próprios consultores em Inteligência Empresarial conflitam diretamente com normas estabelecidas e violam, claramente, padrões éticos ou a própria legislação pública e que o comportamento inescrupuloso na coleta de informação pode levar a uma baixa geral dos padrões éticos da companhia.

Normanha Filho (2004) estudou a relação da ética no marketing com a ética empresarial e concluiu que, apesar de ainda negligenciada no Brasil, a ética no marketing, em função do amadurecimento e consciência da sociedade, está cada vez mais sendo incorporada nas práticas empresariais; Patrus et al. (2013) verificaram avanços, dilemas e possibilidades de aprofundamento da postura ética nos negócios com relação ao tratamento de seus trabalhadores, comprovando que a responsabilidade social empresarial no Brasil é orientada pela ética da responsabilidade.

Ainda, mantendo a ética na empresa, Fernández e Pinuer (2016) corroboraram com a hipótese de que a orientação ao valor do cliente, o valor da marca e a ética empresarial 
influenciam o desempenho organizacional, bem como identificaram que uso rigoroso e adequado de informação pode estar relacionado à ética nos negócios, no momento da coleta e utilização da informação, e se a imagem projetada pela empresa for lembrada e reconhecida como positiva pelos consumidores, o valor da marca será reforçado.

Alves et al. (2007) investigaram a influência do Código de Ética sobre o processo decisório ético profissional de Contabilidade e concluíram que, se o Código de Ética profissional é percebido pelo indivíduo como guia de conduta, ele estará mais propenso a cumprir as normas emanadas do CFC, reduzindo, dessa forma, a possibilidade de ocorrência de ações que prejudiquem os diversos usuários das informações contábeis. Além dessa predisposição para acatar as normas do Código de Ética, fatores como religião, o nível de escolaridade, a cultura organizacional, dentre outros, podem influenciar o processo decisório ético do indivíduo (Alves et al., 2007).

Já Antunes et al. (2011) adentraram no campo da ética em pesquisa com o intuito de conhecer como os acadêmicos do campo das ciências contábeis percebem os aspectos éticos no processo de pesquisa; na orientação de alunos e relação com os seus pares e na disseminação do conhecimento. Os autores perceberam que alguns valores que são considerados importantes não são praticados na mesma intensidade; enquanto outros valores considerados como de extrema importância são intensamente praticados.

Por sua vez, Oliveira e Santos (2007), focando mais na ética contábil, objetivaram confirmar se o rodízio de firmas de auditoria diminui os riscos de perda de independência dos auditores e evitam erros e fraudes na vistoria das demonstrações contábeis. Os resultados demonstraram que a formação ética, o histórico moral e, principalmente, a estrutura emocional como pessoa serão os atributos que definirão se o auditor aceitará conviver com situações que possam ser consideradas inadequadas; o estudo confirma que os aspectos inerentes à natureza humana na vida corporativa e no mundo dos negócios, dimensionados na cobiça, na ambição e na vaidade, são características comuns às pessoas e potencializados no dia a dia do trabalho, podendo fazer prevalecer o interesse pessoal em detrimento do interesse público (Oliveira \& Santos, 2007).

Com a finalidade de averiguar contextos culturais, Ferreira et al. (2012) pretenderam compreender diferenças nas percepções éticas e dimensões culturais entre dois países com culturas latinas: Brasil e Portugal, e concluíram que os brasileiros se revelam mais tolerantes à ambiguidade e mais conscientes das consequências futuras dos seus atos, mas com maior propensão a comportamentos menos éticos. Já Teixeira e Santos (2016) destacaram a importância da inovação nos serviços em Portugal, tendo em vista o atraso do país em termos de desempenho inovador, identificando que a participação em atividades de inovação em cooperação com parceiros estrangeiros emerge como um fator-chave para o desempenho inovador das empresas de serviços.

Por conseguinte, Sampaio e Sobral (2013) discutiram como as características brasileiras estão relacionadas às intenções internas de denúncia em organizações em geral e evidenciaram que características como a aversão ao conflito, a superação das relações interpessoais e a natureza afetiva das pessoas podem contribuir para a compreensão da denúncia como um comportamento inaceitável de muitos funcionários brasileiros.

Ainda, diferentemente dos achados para TCP, a metodologia abordada nos estudos da ética empresarial é mais variada.

Tendo em vista os resultados encontrados, averiguou-se que, no âmbito da ética, as classificações metodológicas empregam pesquisa bibliográfica (Sapiro, 1993; Besen et al., 2015; Harrison et al., 2015); ensaio teórico simples com Filho (2004), e Sampaio e Sobral 
(2013), que objetivaram propor um modelo teórico; e pesquisa de levantamento (ou survey) com abordagem quantitativa (Alves et al., 2007; Oliveira \& Santos, 2007; Antunes et al., 2011; Ferreira et al., 2012; Fernández \& Pinuer, 2016; Teixeira \& Santos, 2016), trabalhando com amostragens e aplicação de questionários.

Ainda, da mesma forma que a TCP, os estudos relacionados à ética empresarial revelam-se mais quantitativos, com destaque apenas para Patrus et al. (2013), que trabalharam com pesquisa qualitativa, por meio de entrevistas, mas, também, com aplicabilidade de questionário.

Dessa forma, tornou-se evidente a escassez de pesquisas qualitativas tanto para a TCP quanto para a ética empresarial nesses periódicos investigados; da mesma forma que os estudos existentes tentam evidenciar e encontrar fatores que influenciam a atitude ética. Assim, revela-se o diferencial dessa pesquisa, em propor, a partir do modelo teórico de Ajzen (1991), uma maneira de avaliar a ação comportamental ética nas instituições, mensurando esse comportamento pelo intermédio de cenários ético-organizacionais e, ainda, moderando, por meio do SCG, a relação entre o comportamento planejado e a ética-organizacional.

Isto posto, apresenta-se as uma proposição de modelo teórico (Figura 1) a ser testado empiricamente após a validação do instrumento de pesquisa por meio de cenários e análise da qualidade do modelo proposto.

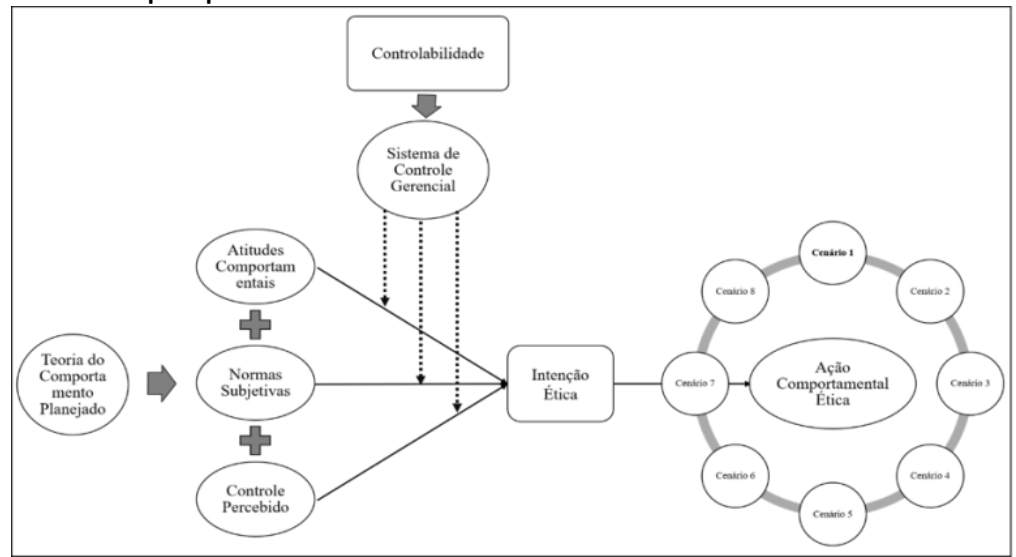

Figura 1. Desenho Teórico da Pesquisa

Destaca-se que o desenho teórico proposto não será testado nessa pesquisa, somente serve de base para aplicabilidade em futuras pesquisas, após validar os instrumentos, a fim de instrumentalizar e operacionalizar o desenho teórico. Porém, infere-se a partir desse desenho futuras hipóteses de pesquisa a serem testadas como contribuição para pesquisas futuras. Ademais, neste momento, levando ao ponto o anseio de instigar futuras pesquisas por meio de elucidações de cenários ou vinhetas (termo utilizado como similar), apresenta-se os oito Cenários a serem validados sobre o tema ética-organizacional.

\begin{tabular}{|c|c|c|c|}
\hline \multirow{9}{*}{$\begin{array}{c}\text { Ética- } \\
\text { Organizacional }\end{array}$} & Cenário Projetista 1 & \multirow{9}{*}{$\begin{array}{l}\text { Haire (1950), Hunt e Vitell (1986) } \\
\text { e Robertson, Zielinski e Ward } \\
\text { (1984) defendem o formato de } \\
\text { cenários projetistas, de modo a } \\
\text { esperar que o respondente } \\
\text { projete seu verdadeiro } \\
\text { sentimento ou crença sobre a } \\
\text { pessoa imaginada, evitando, } \\
\text { assim, a autodefesa. }\end{array}$} & \multirow{7}{*}{$\begin{array}{l}\text { A empregabilidade de } \\
\text { cenários projetistas } \\
\text { proporciona vantagens, } \\
\text { pois despersonaliza a } \\
\text { questão, direcionando o } \\
\text { respondente a uma }\end{array}$} \\
\hline & Cenário Projetista 2 & & \\
\hline & Cenário Projetista 3 & & \\
\hline & Cenário Projetista 4 & & \\
\hline & Cenário Projetista 5 & & \\
\hline & Cenário Projetista 6 & & \\
\hline & Cenário Projetista 7 & & \\
\hline & Cenário Projetista 8 & & resposta franca. \\
\hline & Cenário Projetista 8 & & \\
\hline
\end{tabular}


Cenário Projetista 1 - CP1 - A empresa Xis S.A. liderou com folga o mercado até o ano passado. Foi quando a empresa Zê S.A. (concorrente) desenvolveu um produto superior e com um componente inovador e mais barato. A empresa Xis S.A. espera perder parcela do mercado e seu estoque está abarrotado. Oliver, o controller, sabe que o valor de mercado do estoque cairá bastante, em virtude do produto da concorrência. Ele sabe que deveria reportar o caso dos estoques em seu relatório, porém lembrou-se de ser advertido duramente o ano passado quando informou a diretoria sobre um caso parecido, então, resolveu não evidenciar coisa alguma sobre os estoques desta vez. A alta administração espera seus relatórios para tomada de decisão e planejamento. Oliver deveria continuar essa prática?

Cenário Projetista 2 - CP2 - Oliver é controller de uma grande empresa. Na equipe que ele lidera tem um funcionário de quem gosta especialmente. Suas esposas também são amigas e seus filhos estudam juntos. Oliver, ao definir as premissas orçamentárias e metas, sempre favorece esse funcionário com considerações especiais sobre suas metas, o que Oliver não faz aos demais da equipe. Ele deve continuar esta prática?

Cenário Projetista 3 - CP3 - Ao elaborar a análise de desempenho econômico das áreas da empresa, Oliver constatou que o setor de compras não está com bom desempenho, de acordo com o planejamento desenvolvido. No entanto, Oliver já teve desavenças com o gestor do setor de compras. Oliver então explicou ao seu supervisor que não se sente apto em verificar o desempenho desse setor, pois não consegue separar o profissional do pessoal com relação a esse gestor de compras. Oliver realmente deveria ter relatado ao supervisor essa informação?

Cenário Projetista 4-CP4 - - O superior hierárquico de Oliver avalia o seu trabalho e acredita, erroneamente, que Oliver merece o crédito por ter desenvolvido no sistema da empresa um Modelo de Informação padronizado, o que gerou harmonia ao conjunto de informações gerenciadas por cada setor e, consequentemente, melhoria nos resultados. Oliver levou todo o crédito, mas, na verdade, um funcionário novato que deixou a empresa foi o maior responsável pela consecução do Modelo. Oliver deveria ter esclarecido as coisas?

Cenário Projetista 5 - CP5 - Para finalizar uma negociação de parceria com a grande empresa Hard S.A., Oliver sabe que precisa apresentar melhores resultados em suas demonstrações financeiras. Essa parceria vem sendo cobrada pelo supervisor de Oliver há dois anos e, caso Oliver feche o negócio, ele obterá um aumento salarial. Assim, Oliver decide por manipular os resultados finais na demonstração financeira e, se necessário, ele culpará sua empresa mais tarde. Oliver deve continuar com essa prática?

Cenário Projetista 6 - CP6 - Oliver precisa elaborar a análise de resultado econômico dos produtos e serviços da empresa. Seu superior hierárquico estipulou um prazo de entrega, o qual Oliver não cumpriu. No dia da reunião, Oliver apresenta a análise de resultado econômico do ano anterior para não "levar sermão" pela falta de cumprimento de prazo. $\mathrm{Na}$ reunião, decisões importantes são tomadas em cima dessa análise de resultado do ano anterior. Mesmo acreditando que não houve mudanças significativas nos resultados entre os anos, Oliver deveria esclarecer a situação?

Cenário Projetista 7 - CP7 - Oliver é um controller relativamente inexperiente, que está tendo alguma dificuldade em viver com o que ele avalia ser um salário inferior ao adequado. Oliver ocasionalmente leva a esposa para jantar e cobra da empresa, alegando ter sido um jantar de negócios, afinal raciocina que ele trabalha duro e merece desfrutar de alguns benefícios da empresa. Oliver deveria continuar essa prática?

Cenário Projetista 8 - CP8 - Oliver elaborou a análise de desempenho dos gestores que ele lidera, mas ao entregar o resultado ao seu superior hierárquico, verificou, antes de 
finalizar seu relatório de desempenho, que não preencheu todos os campos solicitados pela empresa para avaliar o desempenho da equipe. Oliver acredita que aquilo que não foi preenchido não fará diferença no resultado e acha que seu superior simplesmente não perceberá a falha. Oliver deve apontar o erro? Isto posto, na sequência são descritos os procedimentos metodológicos aplicados nesse estudo.

\section{METODOLOGIA}

A pesquisa enquadrou-se como descritiva-exploratória (Theodorson \& Theodorson, 1970; Gil, 2009), quantitativa (Soares, 2003), de levantamento (Gil, 2002), por meio da aplicação de um questionário estruturado, com análise da teoria pelo método hipotéticodedutivo (Lakatos \& Marconi, 2000; Creswell, 2007).

Quando uma nova escala é desenvolvida ou adaptada, pesquisadores seguem rigorosos procedimentos para o seu desenvolvimento, bem como para fornecer informações sobre sua confiabilidade e validade. Segundo Mendez et al (2010) a validade de conteúdo tem sido definida como o grau no qual um instrumento tem um apropriado conjunto de itens para representar o constructo a ser mensurado ou ainda a extensão na qual um instrumento representa adequadamente o domínio de interesse. Destaca-se, que essa pesquisa limita-se a validar os oito cenários Etico-Organizacionais, porém os procedimentos adotados foram para todos os constructos do desenho teórico.

A unidade de análise desse estudo é a validade de instrumento de coleta de dados da pesquisa subdividido em perguntas objetivas e projeção de Cenários Ético-Organizacionais. Nesse sentido, o instrumento de pesquisa foi composto por perguntas abertas e fechadas, distribuídas em cinco seções, as quais continham os atributos identificados por meio da literatura e foi submetido a dois pré-testes. Um pré-teste tem como função testar o instrumento de coleta de dados, evidenciando se há ambiguidade entre as questões, perguntas supérfluas ou difíceis de interpretar e a complexidade e amplitude dos questionamentos (Lakatos \& Marconi, 1996). Ainda, o tamanho amostral de um pré-teste deve ser de quatro ou cinco indivíduos, não podendo exceder 30 respostas (Hair Jr. et al., 2005). Antecipadamente a realização do pré-teste o instrumento de coleta de dados passou pelo crivo de três professores com o objetivo de trazer o alinhamento temático, conforme etapas indicadas na Figura 2.

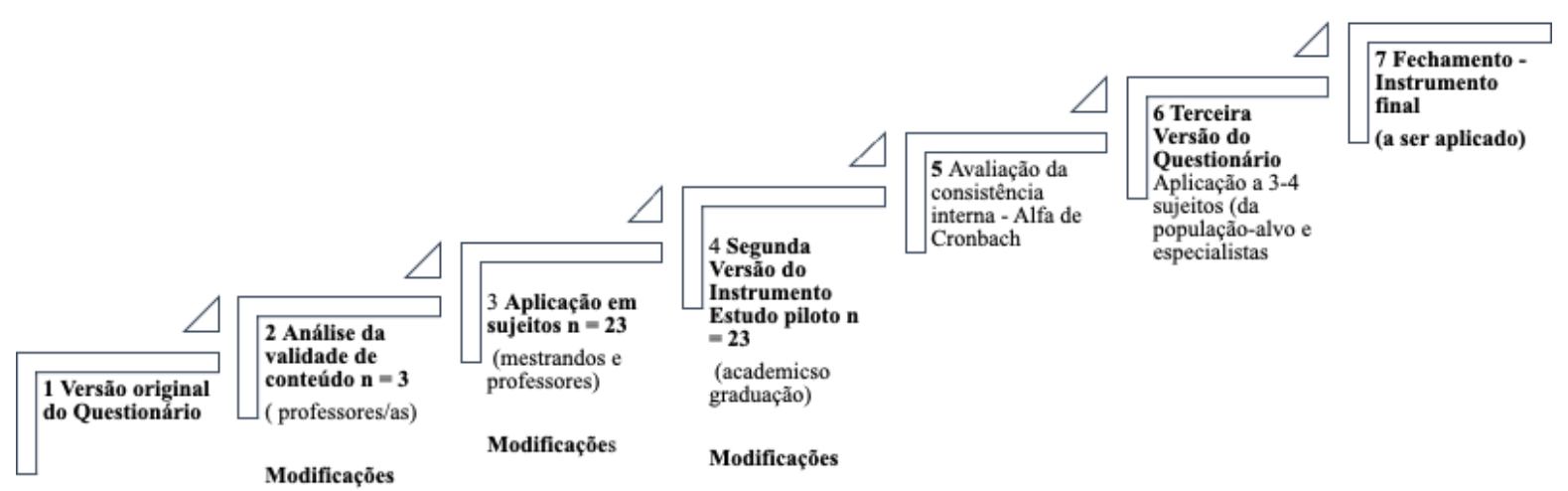

Figura 2. Etapas da Pesquisa - Estudo Piloto

Isto posto, conforme Gil (2009), foram considerados os seguintes aspectos no préteste: clareza e precisão dos termos; quantidade, forma e ordem das perguntas, portanto as estamas seguiram de modificações e ajustes. $O$ instrumento após ter sido submetido à validade de conteúdo foi composto pela medida do comportamento elaborado por meio de 
escalas específicas para cada dimensão, sendo essas de sete pontos, segregadas de acordo com as variáveis do estudo, conforme evidencia o Quadro 1.

Quadro 1 - Constructo da pesquisa

\begin{tabular}{|c|c|c|c|}
\hline Constructo & Elementos & Instrumento & Autores \\
\hline \multirow{4}{*}{$\begin{array}{c}\text { Teoria do } \\
\text { Comportamento } \\
\text { Planejado }\end{array}$} & Atitudes Comportamentais & \multirow{4}{*}{$\begin{array}{c}\text { Escala proposta por } \\
\text { Ajzen (2006) de } 7 \\
\text { pontos }\end{array}$} & \multirow{4}{*}{$\begin{array}{c}\text { Ajzen e Fishbein (1980); } \\
\text { Ajzen (1985); Ajzen (2006) }\end{array}$} \\
\hline & Normas Subjetivas & & \\
\hline & Controle Percebido & & \\
\hline & Intenção Ética & & \\
\hline Ética-Organizacional & Cenários Projetistas & $\begin{array}{l}\text { Escala de Dever de } \\
7 \text { pontos }\end{array}$ & $\begin{array}{l}\text { Robertson e Anderson } \\
\text { (1993) }\end{array}$ \\
\hline $\begin{array}{c}\text { Sistema de Controle } \\
\text { Gerencial }\end{array}$ & Controlabilidade & $\begin{array}{l}\text { Escala Likert de } 7 \\
\text { pontos }\end{array}$ & $\begin{array}{l}\text { Merchant (1987), Simons } \\
\text { (2005), Bisbe, Batista- } \\
\text { Foguet e Chenhall (2007) e } \\
\text { Beuren, Roth e Anzilago } \\
\text { (2017). }\end{array}$ \\
\hline
\end{tabular}

Fonte: as autoras.

Nesse sentido, o questionário teve sua base literária na revisão teórica indicada nessa pesquisa, possuindo como principais referências: Ajzen (2006); Robertson e Anderson (1993); Beuren et al. (2017), Merchant (1987), Simons (2005) e Bisbe et al. (2007), dos quais foram adaptados os questionamentos, tornando as perguntas dessa pesquisa de autoria própria, no entanto, utilizando as mesmas escalas de Ajzen (2006) na segunda seção para avaliar a TCP; de Robertson e Anderson (1993) na terceira seção para mensurar a percepção dos respondentes em relação aos cenários idealizados; e de Beuren et al. (2017), Merchant (1987), Simons (2005) e Bisbe et al. (2007) na quarta seção avaliando a controlabilidade. O Quadro 2 expõe as variações das escalas empregadas.

Quadro 2 - Variações das escalas

\begin{tabular}{|c|c|c|}
\hline Autoria & $\mathbf{1}$ & $\mathbf{7}$ \\
\hline \multirow{2}{*}{ Ajzen (2006) } & Discordo totalmente & Concordo totalmente \\
\cline { 2 - 3 } & Difícil & Fácil \\
\cline { 2 - 3 } & Definitivamente não & Definitivamente sim \\
\hline Robertson e Anderson (1993) & $\begin{array}{c}\text { Definitivamente não } \\
\text { deveria }\end{array}$ & Definitivamente deveria \\
\hline $\begin{array}{c}\text { Beuren et al. (2017), Merchant (1987), Simons (2005) e } \\
\text { Bisbe, Batista-Foguet e Chenhall (2007) }\end{array}$ & Discordo totalmente & Concordo totalmente \\
\hline
\end{tabular}

Fonte: as autoras.

Dessa forma, para a medida da teoria do comportamento planejado utilizou-se do instrumento adaptado de Ajzen (2006); para a mensuração da ética-organizacional foram elaborados oito cenários projetivos, adaptados para a realidade estudada, conforme cenários apresentados por Robertson e Anderson (1993), os quais envolviam situações corriqueiras do cotidiano empresarial, de modo que o cenário projetasse possíveis realidades, no entanto, colocando um personagem protagonista, despersonalizando a questão, utilizando-se, para isso, das funções da Controladoria definidas por Almeida, Parisi e Pereira (2001); e, para medir o sistema de controle gerencial, fez-se o emprego do instrumento adaptado de Merchant (1987), Simons (2005), Bisbe et al. (2007) e Beuren et al. (2017). 
A segunda fase da pesquisa, para proceder com a validade do instrumento final, aplicou-se o instrumento na população alvo composta por profissionais controllers e/ou Chief Executive Officer (CEO's) das 500 Maiores e Melhores da Revista Exame. Além disso, por meio de uma amostragem probabilística aleatória (Malhotra, 2006; Mattar, 2007) e, recorreu-se ao software G*Power, a fim de estimar o tamanho da amostra. Nesse sentido, a amostragem foi definida com avaliação do poder preditivo a priori, adotando-se como parâmetros um grau de confiabilidade de $80 \%$ e margem de erro de $5 \%$ (Ringle, Souza \& Bido, 2014), de modo que o estudo foi baseado em uma amostra de 92 empresas dentre a lista das 500 Maiores e Melhores da Revista Exame, obtida no site da revista. O critério para selecionar as 92 entidades participantes foi por intermédio da função "geração de números aleatórios" do Microsoft Excel.

$\mathrm{O}$ acesso aos respondentes foi por meio do Linkedln. Primeiramente, elaborou-se um quadro com o nome de todas as organizações que formaram a amostra. Posteriormente utilizando-se de recursos de seu próprio Linkedln, buscou conexão com os controllers das respectivas entidades seguindo algumas etapas, conforme evidencia o Quadro 3.

Quadro 3 - Procedimentos de coleta de dados
\begin{tabular}{|l|l|}
\hline 1 & Selecionou em ordem crescente a instituição do quadro amostral. \\
\hline 2 & $\begin{array}{l}\text { No campo “pesquisar" no Linkedln era digitado o nome da organização, sendo que o resultado fornecia } \\
\text { o total de todos os funcionários no Linkedln. }\end{array}$ \\
\hline 3 & $\begin{array}{l}\text { Ao acessar todos os funcionários, no campo "todos os filtros" era digitado "controller" na aba "cargo" e, } \\
\text { após aplicar os filtros, o Linkedln fornecia os controllers da organização escolhida. }\end{array}$ \\
\hline 4 & $\begin{array}{l}\text { A pesquisadora, então, solicitava conexão com o controller e, nesse momento, já encaminhava uma } \\
\text { mensagem convidando para a participação na pesquisa. }\end{array}$ \\
\hline 5 & $\begin{array}{l}\text { Após o controller aceitar a conexão e responder à mensagem de modo positivo em participar da pesquisa, } \\
\text { a pesquisadora enviava o link do questionário. Aos respondentes que responderam à mensagem de modo } \\
\text { negativo à participação na pesquisa, retirou-se o nome da respectiva empresa ligada a esse controller e, } \\
\text { ao final, com as empresas restantes que não haviam sido selecionadas, foi rodada novamente a função } \\
\text { "aleatório entre" no Excel }{ }^{\circledR} \text { até que se atingisse o número amostral. }\end{array}$ \\
\hline
\end{tabular}

Fonte: as autoras.

Isto posto, o tópico subsequente abordou a discussão e análise dos resultados em duas etapas, a primeira análise do instrumento de pesquisa. $E$, a segunda análise do instrumento final, aplicado a população amostral.

\section{ANÁLISE E DISCUSSÃO DOS RESULTADOS}

Nesta seção são apresentados os critérios para a avaliação do modelo de mensuração, por meio da análise e dos ajustes propostos no estudo piloto e pré-teste (especialistas/professores/acadêmicos e representantes amostrais) e por meio da avaliação do modelo de mensuração aos respondentes finais (profissionais - controllers)

\section{1 - Análises de Ajustes propostos - Estudo Piloto}

O estudo piloto foi discutido com três pesquisadores (professores) para julgarem o mérito dos elementos teóricos e delineamento de entendimentos técnicos. Após o crivo da equipe de pesquisadores aplicou-se o primeiro pré-teste via e-mail, sendo encaminhado para professores e pós graduandos de ensino superior com atividades em programa de mestrado na área contábil. Obteve-se 23 respostas, sendo que, para cada seção do questionário, os 
respondentes poderiam realizar apontamentos.

Nesse sentido, tendo em vista que os aconselhamentos dos respondentes do primeiro pré-teste foram significativos, inclusive elementos foram retiradas e escalas precisariam ser reanalisadas, optou-se por realizar os ajustes e enviar a um segundo pré-teste a segunda versão do questionário.

Dessa forma, o segundo pré-teste foi aplicado via e-mail, o grupo amostral nessa etapa foi modificado, tendo em vista as contribuições e ajustes incorporados ao primeiro pré-teste. Esse procedimento buscou incorporar as sugestões de melhoria principalmente devido a questões com dificuldades de compreensão e linguagem e discussões técnicas. A opção de, em um segundo momento, realizar o pré-teste com alunos da graduação, se deu a fim de verificar a compreensão de cada questionamento, conseguindo perceber se a pesquisadora facilitou o entendimento para cada pergunta. A aplicabilidade do 2‥ Pré-teste teve o alcance para 40 respondentes, os quais eram alunos do quarto ano da graduação em Ciências Contábeis da Unioeste, com um retorno válido de 23.

O Quadro 4 apresenta as sugestões realizadas pelos respondentes à primeira versão do questionário do primeiro pré-teste, o qual estava com ordem diferenciada nas seções.

Quadro 4. Primeiro pré-teste para a primeira versão do questionário

\begin{tabular}{|l|l|}
\hline Seção & Sugestões \\
\hline 1: Perfil e questões abertas & $\begin{array}{l}\text { Essa primeira seção possuía, além das questões de perfil, seis questões } \\
\text { abertas sobre consciência ética e SCG. Os conselhos foram no sentido de } \\
\text { refazer essas questões, pois estavam generalizadas e tendenciosas. }\end{array}$ \\
\hline Planejado Teoria do Comportamento & $\begin{array}{l}\text { Os questionamentos sobre a TCP receberam críticas pela mudança de } \\
\text { escala, contudo, isso não foi alterado, tendo em vista essa ser a escala de } \\
\text { "norma subjetiva", visto que, esse acréscimo melhoraria a mensuração. } \\
\text { Foram realizados alguns ajustes no modo de escrever as assertivas, } \\
\text { deixando-as mais compreensivas. }\end{array}$ \\
\hline 3: Cenário ético-organizacional & $\begin{array}{l}\text { Nessa primeira versão do questionário foram formulados apenas três } \\
\text { cenários, embasados em Cohen, Pant e Sharp (1996), utilizando-se da } \\
\text { Escala Ética Multidimensional de Reidenbach e Robin (1990); as sugestões } \\
\text { foram unânimes em afirmar que os casos elaborados estavam confusos e } \\
\text { de difícil compreensão, além de criticarem negativamente a escala } \\
\text { empregada, afinal (como já delineado no tópico 2.3 do referencial teórico) } \\
\text { essa escala é subdivida em três dimensões, totalizando oito categorias } \\
\text { diversificadas que oscilam entre o que é ético, moral, honesto, justo, tácito, } \\
\text { entre outras, o que dificultou as respostas. Dessa forma, diante dos } \\
\text { aconselhamentos, os cenários foram reelaborados. }\end{array}$ \\
\hline
\end{tabular}




\begin{tabular}{|l|l|}
\hline 4: Sistema de Controle & $\begin{array}{l}\text { Apresentou questionamentos acerca do SCG, o qual, para a primeira versão } \\
\text { do questionário, era mensurado de acordo com duas variáveis: } \\
\text { controlabilidade e lócus de controle; a subseção controlabilidade recebeu } \\
\text { apontamentos na formulação da questão, por estarem longas, com muitos } \\
\text { conectivos e arbitrárias; já a subseção lócus de controle, até então colocada } \\
\text { como variável para SCG, foi recomendada ser retirada, visto que, de acordo } \\
\text { com as sugestões, as perguntas estavam muito pessoais, não estimavam } \\
\text { expectativas de comportamento e ficaram repetitivas, de modo que a } \\
\text { pesquisadora refez as questões dessa subseção. }\end{array}$ \\
\hline
\end{tabular}

Fonte: as autoras.

Destarte, a pesquisadora obteve novamente um retorno de 23 respostas, sendo que, para cada seção do questionário, os respondentes poderiam realizar apontamentos. O Quadro 5 apresenta as sugestões realizadas pelos respondentes à segunda versão do questionário do segundo pré-teste.

\section{Quadro 5. Segundo pré-teste para a segunda versão do questionário}

\begin{tabular}{|c|c|}
\hline Seção & Sugestões \\
\hline 1: Perfil & $\begin{array}{l}\text { Essa primeira seção da segunda versão do questionário apresentou } \\
\text { questões do perfil apenas, para as quais não foram necessários reajustes; } \\
\text { as seis perguntas abertas sobre consciência ética e SCG foram realocadas } \\
\text { na última seção do questionário, não sendo de preenchimento obrigatório. }\end{array}$ \\
\hline $\begin{array}{l}\text { 2: Teoria do Comportamento } \\
\text { Planejado }\end{array}$ & $\begin{array}{l}\text { Os questionamentos sobre TCP na segunda seção, após as adaptações } \\
\text { solicitadas no primeiro pré-teste, foram aprovados. }\end{array}$ \\
\hline 3: Cenário ético-organizacional & $\begin{array}{l}\text { A terceira seção com os cenários éticos-organizacionais foi reestruturada } \\
\text { com novos cenários e nova escala, tendo em vista os apontamentos ao } \\
\text { primeiro pré-teste; manteve-se a Escala Ética Multidimensional } \\
\text { (Reidenbach \& Robin, 1990), contudo, a escala estabelecida por Robertson } \\
\text { \& Anderson (1993) foi acrescentada, de modo que para cada cenário } \\
\text { possuía um total de nove escalas; os cenários foram reconstruídos de } \\
\text { acordo com Robertson e Anderson (1993) e Almeida et al. (2001). Destarte, } \\
\text { para os cenários as críticas foram positivas, todos estavam de fácil } \\
\text { compreensão, já para as escalas os respondentes foram unânimes em } \\
\text { sugerir a retirada da Escala Ética Multidimensional, com a justificativa de } \\
\text { que essa escala apresentou ambiguidade e julgou não apenas a ética, mas } \\
\text { também a moralidade, a justiça, a honestidade, entre outros aspectos que } \\
\text { fogem do tema pesquisado. Assim, as pesquisadoras, analisaram essas } \\
\text { afirmativas e ambas optaram pela exclusão da escala proposta por } \\
\text { Reidenbach e Robin (1991) para mensurar ética nessa pesquisa. }\end{array}$ \\
\hline $\begin{array}{l}\text { 4: Sistema de Controle } \\
\text { Gerencial }\end{array}$ & $\begin{array}{l}\text { A quarta seção apresentou perguntas acerca do SCG, sendo subdividida em } \\
\text { controlabilidade e lócus de controle; para a subseção controlabilidade } \\
\text { foram novamente sugeridas alterações na escrita, de modo que as } 10 \\
\text { questões foram mantidas, no entanto, todas foram readaptadas com uma } \\
\text { escrita mais coerente e simples; a subseção lócus de controle, mesmo após } \\
\text { os reajustes nos questionamentos, continuou com a sugestão no segundo }\end{array}$ \\
\hline
\end{tabular}




\begin{tabular}{|l|l|}
\hline 5: Análise geral & $\begin{array}{l}\text { pré-teste de ser retirada, de maneira que as pesquisadoras, analisaram e } \\
\text { ambas concluíram pela remoção desse elemento. }\end{array}$ \\
\hline & $\begin{array}{l}\text { Essa seção foi criada para a segunda versão do questionário e mantida, } \\
\text { contendo três questões abertas perguntando sobre o uso dos sistemas de } \\
\text { controle gerencial na organização do respondente. }\end{array}$ \\
\hline
\end{tabular}

Fonte: as autoras.

Isto posto, conforme Gil (2009), foram considerados os seguintes aspectos no préteste: clareza e precisão dos termos; quantidade, forma e ordem das perguntas. Dessa maneira, as sugestões ao questionário foram, de modo geral, acatadas, o que aprimorou a versão final do questionário.

Sendo assim, a primeira versão do questionário possuía 45 questões e 3 cenários com oito escalas de assertiva no total; já a segunda versão foi formada por 46 questões e 8 cenários com nove escalas de assertiva em sua totalidade; após os reajustes necessários, a terceira e última versão do instrumento de pesquisa dessa pesquisa ficou estruturada com 41 questionamentos e 8 cenários com uma única escala.

Nesse sentido, o instrumento de pesquisa foi concluído e encaminhado aos controllers. No total, 256 questionários foram enviados por meio do Linkedln à amostra delimitada, de modo que obteve-se 105 respostas.

\subsection{Análise do Modelo de Mensuração}

De acordo com Hair et al. (2014), para os modelos de medição refletiva existem quatro estágios de critérios que precisam ser verificados de maneira sistemática, a fim de validar o modelo de medição. 0 Quadro 6 apresenta esses estágios.

Quadro 6. Avaliação Sistemática dos Resultados

\begin{tabular}{|l|l|}
\hline \multicolumn{2}{|c|}{ Avaliação Sistemática dos Resultados } \\
\hline \multicolumn{2}{|c|}{ Etapa: Avaliação dos Modelos de Medição } \\
\hline \multicolumn{2}{|c|}{ Estágios para Medição Refletiva } \\
\hline 1 - Consistência interna (confiabilidade composta) & 3 - Validade convergente (variância média extraída) \\
\hline 2 - Confiabilidade do indicador & 4 - Validade Discriminante \\
\hline
\end{tabular}

Fonte: Adaptado de Hair et al. (2014).

Sendo assim, após rodar os dados no conforme o desenho teórico proposto nessa pesquisa, foram realizadas as análises dos critérios apresentados no Quadro 6, de modo que a avaliação do modelos de medição reflexiva incluiu confiabilidade composta que avaliou a consistência interna, a confiabilidade do indicador individual e a variância média extraída (AVE) que verificou a validade convergente e o critério de Fornell-Larcker foi utilizado para avaliar a validade discriminante.

A primeira análise iniciou-se a partir da observação dos valores da consistência interna e a confiabilidade composta. $O$ indicador tradicional para a consistência interna é o Alfa de Cronbach, o qual se baseia em intercorrelações das variáveis; já a confiabilidade composta é verificada por meio da fiabilidade composta. Ambos os indicadores são empregados para 
avaliar se a amostra está livre de vieses ou se o conjunto de respostas são confiáveis (Ringle et al., 2014). A Tabela 1 evidencia seus valores.

Tabela 1 - Consistência Interna e Confiabilidade Composta

\begin{tabular}{lll}
\hline Variáveis & Alfa de Cronbach & Fiabilidade composta \\
\hline Atitudes Comportamentais & 0,734 & 0,842 \\
Cenário Ético-organizacional & 0,842 & 0,897 \\
Controle Percebido & 0,362 & 0,750 \\
Intenção Ética & 0,447 & 0,770 \\
Normas Subjetivas & 0,049 & 0,700 \\
\hline
\end{tabular}

Fonte: Elaborado pela autora a partir dos dados da pesquisa (2018).

Observa-se, na Tabela 1, que a confiabilidade composta apresentou todos seus valores acima de 0,7 , o que é defendido por Hair et al. (2014) como um resultado satisfatório de confiabilidade dos constructos. Em relação ao Alfa de Cronbach, Nunnally e Bernstein (1994) afirmam que valores entre 0,6 e 0,7 são aceitáveis em pesquisas exploratórias. Dessa forma, os valores do Alfa para os constructos Atitudes Comportamentais e Cenário Éticoorganizacional foram considerados adequados e livres de vieses.

Por outro lado, as variáveis Controle Percebido, Intenção Ética e Normas Subjetivas revelaram um Alfa abaixo de 0,6 . A essas ocorrências de valores baixos, Hora, Monteiro e Arica (2010) ressaltam que ainda não existe um consenso entre os pesquisadores com relação à interpretação da confiabilidade de um instrumento de pesquisa obtida por meio do valor do Alfa de Cronbach. E, ainda, elencam que existem autores que recorrem ao Alfa como medida de confiabilidade, contudo, não mencionam o mínimo estipulado para tal indicador (Miguel \& Salomi, 2004; Salomi, Miguel, \& Abackerli, 2005).

Sendo assim, Maroco e Garcia-Marques (2006) defendem que quanto menor for a soma das variâncias dos itens, maior é o coeficiente Alfa, sendo que a soma da variância dos itens está relacionada à variância dos itens e ao número de itens do instrumento. Destarte, justificam-se os constructos Controle Percebido, Intenção Ética e Normas Subjetivas apresentarem um baixo valor de Alfa, visto que ambos evidenciaram variações com relação às respostas obtidas para esses indicadores.

Nesse sentido, Hair et al. (2014) e Ringle et al. (2014) apontam que devido às limitações do Alfa de Cronbach, é mais apropriada uma medida diferente de confiabilidade de consistência interna, chamada de confiabilidade composta. Valores aceitáveis de confiabilidade composta mantêm-se em torno de 0,7 e 0,9 (Nunnally \& Bernstein, 1994), de modo que, conforme se verificou na Tabela 1 , a confiabilidade composta revelou valores acima de 0,7 sendo considerada satisfatória para o modelo de medição.

Por conseguinte, a segunda análise realizada foi na confiabilidade dos indicadores, a qual é uma característica das cargas externas do constructo e indicam que seus indicadores associados possuem comunalidade (Hair et al., 2014). As cargas externas de todos os indicadores precisam ser estatisticamente significantes.

Em concordância com Hair et al. (2014), a carga externa de um indicador precisa estar acima de 0,7 para ser considerado aceitável. Dessa forma, os autores defendem a exclusão cuidadosa dos indicadores, de modo que os itens com cargas externas entre 0,4 e 0,7 serão removidos apenas se a exclusão aumentar a confiabilidade composta ou a variância média extraída e itens com cargas externas abaixo de 0,4 devem sempre ser eliminados (Hair Jr., Ringle, \& Sarstedt, 2011; Hair et al, 2014). 
Assim, de acordo com o modelo estrutural rodado nesse software, do total de 31 indicadores para os constructos (a variável controlabilidade foi colocada apenas para verificar as cargas fatoriais de seus indicadores, visto que é uma moderadora), 10 foram retirados devido às cargas externas abaixo de 0,4.

Os constructos Atitudes Comportamentais e Intenção Ética foram os únicos que mantiveram todos os seus indicadores. Para a variável Normas Subjetivas foi necessária a exclusão de duas questões, portanto, as Normas Subjetivas foram mensuradas pela NS $2.4 \mathrm{e}$ NS 2.7; já no constructo Comportamento Planejado, duas questões também foram retiradas, sendo mensurado pelos itens CP 2.9 e CP 2.11. A variável dependente Cenário Éticoorganizacional teve três de seus cenários excluídos, ajustou-se essa mensuração a cinco indicadores: C1, C2, C4, C5, e C7. A variável moderadora (inclusa somente na análise de moderação) teve a exclusão de três questões, mensuradas pelos itens Co 4.1.2, Co 4.1.3, Co 4.1.4, Co 4.1.6, Co 4.1.8, Co 4.1.9, Co 4.1.10.

Após essas exclusões de indicadores com cargas externas inferiores, procedeu-se a validade convergente, mensurada por meio da AVE. De acordo com Ringle et al. (2014), a AVE é a média das cargas fatoriais elevada ao quadrado, de maneira que, para se elevar o valor da AVE, devem ser eliminadas as variáveis com cargas externas de menor valor.

A AVE inclui a variância de seus indicadores "capturada por meio do constructo em relação à quantidade total da variância, incluindo a variação devido ao erro de medição" (Götz, Liehr-Gobbers, \& Krafft, 2010, p. 696); assim, uma AVE inferior a 0,5 é considerada insuficiente. Na Tabela 2, evidenciam-se os valores encontrados para o AVE dos constructos dessa pesquisa.

Tabela 2 - Validade Convergente

\begin{tabular}{ll}
\hline Variáveis & Variância Média Extraída (AVE) \\
\hline Atitudes Comportamentais & 0,652 \\
Cenário Ético-organizacional & 0,655 \\
Controle Percebido & 0,604 \\
Intenção Ética & 0,632 \\
Normas Subjetivas & 0,513 \\
\hline
\end{tabular}

Fonte: Elaborado pela autora a partir dos dados da pesquisa (2018).

Pode-se observar, na Tabela 2, que todos os valores da AVE foram superiores a 0,5, conclui-se, então, que os indicadores se correlacionam positivamente com seus constructos e cada constructo explica ao mínimo $50 \%$ da variância dos indicadores atribuídos.

À vista disso, o último critério analisado para a avaliação do modelo de medição foi a validez discriminante, ou seja, o quanto um constructo é verdadeiramente distinto de outros constructos (Hair et al., 2014). De acordo com Ringle et al. (2014), existem dois métodos para se calcular a validez discriminante:

método das cargas cruzadas (Cross Loading): as cargas externas de um indicador no seu respectivo constructo devem ser maiores que todas as suas cargas em outro constructo (Chin, 1998);

método do Fornell-Larcker: desenvolvido por Fornell e Larcker (1981), compara-se a raiz quadrada dos valores da AVE com as correlações das variáveis latentes, sendo que as raízes quadradas das AVE's devem ser maiores que as correlações entre os constructos; a ideia desse método é que um constructo compartilha mais variação com seus próprios indicadores do que com qualquer outro constructo (Hair et al., 2014; Ringle et al., 2014). 
Assim, na Tabela 3 demonstra-se que há validade discriminante entre os constructos, por meio da análise do método de cargas cruzadas (valores destacados em negrito).

Tabela 3 - Validez Discriminante: método cargas cruzadas

\begin{tabular}{|c|c|c|c|c|c|}
\hline Indicador & $\begin{array}{l}\text { Atitudes } \\
\text { Comportamentais }\end{array}$ & $\begin{array}{l}\text { Cenário Ético- } \\
\text { organizacional }\end{array}$ & $\begin{array}{l}\text { Controle } \\
\text { Percebido }\end{array}$ & Intenção Ética & $\begin{array}{l}\text { Normas } \\
\text { Subjetivas }\end{array}$ \\
\hline AC 2.1 & 0,521 & 0,045 & 0,017 & 0,113 & $-0,098$ \\
\hline AC 2.2 & 0,917 & 0,127 & 0,177 & 0,327 & $-0,044$ \\
\hline AC 2.3 & 0,919 & 0,203 & 0,189 & 0,274 & 0,037 \\
\hline $\mathrm{C} 1$ & 0,048 & 0,618 & 0,341 & 0,260 & 0,050 \\
\hline $\mathrm{C} 2$ & 0,119 & 0,943 & 0,578 & 0,215 & 0,180 \\
\hline C4 & 0,247 & 0,392 & 0,258 & 0,349 & 0,116 \\
\hline C5 & 0,173 & 0,967 & 0,621 & 0,292 & 0,174 \\
\hline C7 & 0,147 & 0,956 & 0,591 & 0,293 & 0,196 \\
\hline CP 2.11 & 0,187 & 0,176 & 0,665 & 0,526 & 0,171 \\
\hline CP 2.9 & 0,120 & 0,695 & 0,875 & 0,368 & 0,298 \\
\hline | 2.12 & 0,310 & 0,316 & 0,535 & 0,909 & 0,258 \\
\hline | 2.13 & 0,173 & 0,178 & 0,284 & 0,661 & 0,178 \\
\hline NS 2.4 & 0,139 & 0,119 & 0,189 & 0,243 & 0,695 \\
\hline NS 2.7 & $-0,160$ & 0,146 & 0,257 & 0,160 & 0,737 \\
\hline
\end{tabular}

Fonte: Elaborado pela autora a partir dos dados da pesquisa (2018).

Da mesma forma, quando observada pelo critério de Fornell-Larcker, a validade discriminante continua consistente, visto que todos os valores apurados na diagonal principal (destacados em negrito) são maiores do que as demais correlações, conforme verifica-se na Tabela 4.

Tabela 4 - Validez discriminante: critério de Fornell-Larcker

\begin{tabular}{cccccc}
\hline Variáveis & $\begin{array}{c}\text { Atitudes } \\
\text { Comportamentais }\end{array}$ & $\begin{array}{c}\text { Cenário Ético- } \\
\text { organizacional }\end{array}$ & $\begin{array}{c}\text { Controle } \\
\text { Percebido }\end{array}$ & $\begin{array}{c}\text { Intenção } \\
\text { Ética }\end{array}$ & $\begin{array}{c}\text { Normas } \\
\text { Subjetivas }\end{array}$ \\
\hline $\begin{array}{c}\text { Atitudes } \\
\begin{array}{c}\text { Comportamentais } \\
\text { Cenário Ético- }\end{array}\end{array}$ & 0,808 & 0,000 & 0,000 & 0,000 & 0,000 \\
$\quad$ organizacional & 0,170 & 0,809 & 0,000 & 0,000 & 0,000 \\
$\begin{array}{c}\text { Controle Percebido } \\
\text { Intenção Ética }\end{array}$ & 0,184 & 0,619 & 0,777 & 0,000 & 0,000 \\
Normas Subjetivas & 0,318 & 0,325 & 0,543 & 0,795 & 0,000 \\
\hline
\end{tabular}

Fonte: Elaborado pela autora a partir dos dados da pesquisa (2018).

Nesse sentido, após a verificação da validade discriminante como adequada em ambos os métodos adotados e, ainda, tendo sido explanados os critérios defendidos por Hair Jr. et al. (2014) para validar o modelo de mensuração.

Assim após análises do instrumento de coleta de dados (conteúdo do questionário piloto e pré-testes) bem como da validação do desenho teórico (Consistência interna (confiabilidade composta) - Validade convergente (variância média extraída) - Confiabilidade do indicador e Validade Discriminante infere-se, ao instrumento, a validez ferramental de conteúdo, ou seja o instrumento é uma ferramenta válida e compreensível pelos controllers, com conceitos que apresentam evidência de consistência interna. 


\section{3 - Discussão}

O objetivo da pesquisa consiste em discutir a validação do instrumento de pesquisa possível de captar a controlabilidade (SCG) como propulsora do alinhamento entre o comportamento planejado e cenário ético-organizacionais.

Uma das etapas analíticas do estudo foi apresentar o desenvolvimento, bem como a análise de conteúdo da confiabilidade de um instrumento desenvolvido para o estudo dos determinantes do comportamento planejado em cenários ético-organizacionais. Os achados demonstram que se trata de um instrumento conceitualmente valido, compreensível para os controllers, e coerente nos atributos que mensura.

Quando uma nova escala é desenvolvida, ou adaptada pesquisadores seguem rigorosos procedimentos para o seu desenvolvimento, bem como para fornecer informações sobre sua confiabilidade e validade.

Após discutir a construção de cenários para mensuração do comportamento éticoorganizacional, possível de captar a controlabilidade como propulsor do comportamento planejado destaca-se que a utilização de um instrumento, como o que foi desenvolvido e testado na presente pesquisa, pode auxiliar na deteç̧ão de SCG (controlabilidade) capaz de proporcionar fatores influenciadores do comportamento planejado em um cenário éticoorganizacionais a fim de engajar-se ao alinhamento de interesses organizacional.

É possível que estes fatores se modifiquem na medida em que o cenário éticoorganizacionais se modifique, e que, portanto, estratégias distintas precisam ser empregadas nos diferentes cenários ético-organizacionais e outros elementos de controlabilidade poderiam ser incorporados. Isso posto, justifica-se uma vez que estar ligada ao comportamento, atitude, norma subjetiva e controle percebido (Ajzen, 1985), o pressuposto fundamental da ética é que o indivíduo detém o controle dos fatores que influenciam as escolhas que faz, sendo provável que seus princípios éticos sejam postos à prova ao enfrentar situações de dilemas éticos, (Ghillyer, 2015), como no caso de Oliver, protagonista dos cenários no questionário instrumento dessa pesquisa. Oliver tinha conhecimento que sua tomada de decisão provavelmente acarretaria algum tipo de prejuízo, que estaria abandonando algum valor ético, alguma norma subjetiva, mas optou por relativizar a ética e agir em benefício próprio, tomando para si a resposta ao seu dilema: "dos males o menor".

Em uma análise contextual, pode-se dizer que o Brasil está estarrecido com a sucessão de episódios envolvendo o que é possível chamar de relativização da ética, da aplicabilidade do dialeto "dos males o menor", da corrupção endêmica que assola o país: mensalão, máfia das ambulâncias, indústria de liminares, corrupção e lavagem de dinheiro das empreiteiras, caso Petrobrás, delações premiadas. Vê-se uma extensa lista de funcionários públicos, alguns membros do próprio judiciário, enlameando seus nomes e deixando de lado o ilibado caráter para atender pedidos que, no mínimo, ferem os bons costumes.

Destarte, mesmo que o comportamento seja da vontade do indivíduo, caso não esteja sob seu controle total, a força da relação entre a intenção e o comportamento é reduzida (Rocha et al., 2008). Mesmo assim, mantém-se o argumento da intervenção dos sistemas de controle gerencial, haja vista serem mecanismos que influenciam o comportamento humano (controles informais), implementam estratégias e alinham as metas organizacionais (controles formais) (Anthony \& Govindarajan, 2008; Beuren \& Teixeira, 2014), desde que desenvolvidos de modo a criar uma cultura corporativa de confiança e alinhamento do cenário eticoorganizacionais.

Dada as conclusões acima, essa pesquisa contribui teórica, empírica e socialmente. Primeiro, quanto ao aspecto teórico pode-se verificar que o cenário ético-organizacionais 
contribui para o entendimento do alinhamento do cenário ético-organizacional, possível de captar a controlabilidade como propulsor do comportamento planejado.

Em segundo, quanto ao estudo empírico foi possível observar a relevância da éticaorganizacional reconhecida pelos respondentes dessa pesquisa, bem como foi possível de refletir sobre a construção e adaptação de instrumentos de pesquisa no campo da ética organizacional, controle gerencial e aspectos comportamentais em estudos e pesquisas contábeis. Ademais, a contribuição desse estudo é justamente coletar dados via instrumento de pesquisa por meio de cenários etico-organizacionais a fim de apresentar aos participantes cenários cuidadosamente construídos e realistas para avaliar as intenções, atitudes e comportamentos, aumentando assim o realismo instrumental. Portanto, o estudo contribui de forma empírica pela proposição de cenários projetistas (simuladores de uma situação hipotética) por neutralizar a percepção pessoal do respondente ao avaliar SCG e ética restrito a sua percepção comportamental.

Em terceiro, a contribuição social pauta-se na identificação das limitações do controle gerencial utilizado como garantia de incorporação ética na cultura da organização, de maneira que o SCG revelou-se como importante para as entidades, no entanto, a preocupação com quem opera o sistema se sobressaiu na percepção de que o próprio sistema pode ser manipulado em direção a vertentes antiéticas, comprovando a necessidade da construção de uma relação de confiança e alinhamento de interesses entre administração, colaborador e sociedade.

Como sugestão para pesquisas futuras, recomenda-se que sejam exploradas outras variáveis ao modelo teórico proposto por esse estudo, como, por exemplo, cultura (no âmbito social) e relativização (no âmbito organizacional) e validadas. Além disso, a aplicação dos cenários propostos nesse trabalho juntamente com outras teorias ou em outro contexto social e, ainda, nesse mesmo tema, avaliar o sistema de controle gerencial das organizações, de modo a verificar se um controle gerencial frágil afeta o desempenho das pessoas e da organização. E, por fim analisar, testar e discutir os resultados do desenho teórico proposto validado e consubstanciado, bem como propor hipóteses ao desenho da pesquisa a serem testadas empiricamente.

\section{REFERÊNCIAS}

Ajzen, I. (1985). From intentions to actions: A theory of planned behavior. Action control, 4, 11-39.

Ajzen, I. (1991). The theory of planned behavior. Organizational behavior and human decision processes, 50(2), 179-211.

Ajzen, I. (2002). Residual effects of past on later behavior: Habituation and reasoned action perspectives. Personality and social psychology review, 6(2), 107-122.

Ajzen, I. (2006). Consumer attitudes and behavior. Handbook of consumer psychology, 1 , 525-548.

Ajzen, I., \& Fishbein, M. (1980). Understanding attitudes and predicting social behaviour. New York, MH: Pearson Prentice Hall.

Ajzen, I., \& Madden, T. (1986). Prediction of goal-directed behavior: Attitudes, intentions, and perceived behavioral control. Journal of Experimental Social Psychology, 22, 453474.

Almeida, L. B., Parisi, C., \& Pereira, C. A. (2001). Controladoria. In A. Catelli (Coord.), Controladoria: uma abordagem da Gestão Econômica GECON (pp.343-355). São Paulo, 
SP: Atlas.

Almeida, S. R. V, \& Alves, F.J. dos S. (2014). Testando o Triângulo de Cressey no contexto da convergência às normas internacionais de contabilidade: um estudo empírico sobre comportamento ético de profissionais de contabilidade. Revista de Administração da Universidade Federal de Santa Maria, 8(2), 282-297.

Alves, A. B. (2010). Desenho e uso dos sistemas de controle gerencial e sua contribuição para a formação e implementação da estratégia organizacional. Dissertação de Mestrado em Contabilidade. Faculdade de Economia, Administração e Contabilidade de São Paulo, SP, Brasil.

Andrade, Z. A. F. (2009). A Gestão da Ética Organizacional: possibilidades de atuação dos profissionais de comunicação organizacional e relações públicas. Intercom-XXXII Congresso Brasileiro de Ciências da Comunicação-Curitiba, PR-4 a 7 de setembro.

Anthony, R. N., \& Govindarajan, V. (2008). Sistemas de controle gerencial. São Paulo, SP: AMGH.

Argandoña, A. R. (1994). La ética en la empresa, Madrid: Instituto de Estudos Económicos.

Armitage, C. J., \& Conner, M. (1999). The theory of planned behaviour: Assessment of predictive validity and'perceived control. British journal of social psychology, 38(1), 3554.

Bandura, A. (1990). Selective activation and disengagement of moral control. Journal of Social Issues, 46(1), 27-46.

Barroso, L. B. (2018). Discurso de Barroso na posse de Dias Toffoli no Supremo. Recuperado em 15 de novembro, 2018, de https://www.conjur.com.br/2018-set-13/leia-discursobarroso-posse-dias-toffoli-supremo.

Bisbe, J., Batista-Foguet, J. M., \& Chenhall, R. (2007). Defining management accounting constructs: A methodological note on the risks of conceptual misspecification. Accounting, organizations and society, 32(7-8), 789-820.

Beuren, I. M., Klein, L., Lara, F. L., \& Almeida, L. B. (2016). Percepção de justiça nos sistemas de controle gerencial aumenta comprometimento e confiança dos gestores?. RACRevista de Administração Contemporânea, 20(2), 216-237.

Beuren, I. M., Roth, T. C., \& Anzilago, M. (2017). Efeitos da aplicação do princípio da controlabilidade no desempenho gerencial mediada pelo conflito e ambiguidade de papéis. Revista Universo Contábil, 13(3), 6-28.

Beuren, I. M., \& Teixeira, S. A. (2014). Avaliação dos Sistemas de Controle Gerencial em Instituição de Ensino Superior com o Performance Management and Control. Revista de Gestão da Tecnologia e Sistemas de Informação, 11(1), 169-192.

Blanthorne, C., \& Kaplan, S. (2008). An egocentric model of the relations among the opportunity to underreport, social norms, ethical beliefs, and underreporting behavior. Accounting, Organizations and Society, 33(7), 684-703.

Borges, E., \& Medeiros, C. (2007). Comprometimento e ética profissional: um estudo de suas relações juntos aos contabilistas. Revista Contabilidade \& Finanças-USP, 18(44), 60-71.

Buchan, H. F. (2005). Ethical decision making in the public accounting profession: An extension of Ajzen's theory of planned behavior. Journal of Business Ethics, 61(2), 165181.

Burkert, M., Fischer, F. M., \& Schäffer, U. (2011). Application of the controllability principle and managerial performance: The role of role perceptions. Management accounting research, 22(3), 143-159.

Canary, D. J., \& Seibold, D. R. (1984). Attitudes and behaviour: A comprehensive 
bibliography. New York: Praeger.

CFC - Conselho Federal de Contabilidade. Norma Brasileira de Contabilidade NBC PG 100, de 24 de janeiro de 2014. Dispõe sobre a NBC PG 100 - Aplicação Geral aos Profissionais da Contabilidade. Recuperado em 15 de novembro, 2018, de http://www1.cfc.org.br/sisweb/SRE/docs/NBCPG100.pdf.

Chaia, V. L. M., \& Chaia, M. W. (2000). Mídia e política. Comilla, CO: Universidad Pontifica Comillas.

Cioccari, D. (2015). Operação Lava Jato: escândalo, agendamento e enquadramento. Revista Alterjor, 12(2), 58-78.

Clemen, R. T. (1996). Making hard decisions: an introduction to decision analysis. Duxbury, $\mathrm{OH}$ : Pacific Groove.

Creswell, J. W. (2007). Projeto de pesquisa: métodos qualitativo, quantitativo e misto. Porto Alegre, RS: Artmed.

Cruz, C. A., Shafer, W. E., \& Strawser, J. R. (2000). A multidimensional analysis of tax practitioners' ethical judgments. Journal of Business Ethics, 24(3), 223-244.

Doll, J., \& Ajzen, I. (1992). Accessibility and stability of predictors in the theory of planned behavior. Journal of Personality and Social Psychology, 63(5), 754-758.

Fishbein, M., \& Ajzen, I. (1975). Attitudes towards objects as predictors of single and multiple behavioral criteria. Psychological review, 81(1), 59-66.

Fishbein, M., Ajzen, I., \& Hinkle, R. (1980). Predicting and understanding voting in American elections: Effects of external variables. Understanding attitudes and predicting social behavior, (4), 173-195.

Flynn, L. M. (2001). An empirical investigation of the impact of environment on individual ethical analysis by corporate accountants and human resource managers (Tese de Doutorado). State University of New York at Binghampton.

Ghillyer, A. W. (2015). Ética nos negócios. Porto Alegre, RS: AMGH.

Gibson, A. M., \& Frakes, A. H. (1997). Truth or consequences: A study of critical issues and decision making in accounting. Journal of Business Ethics, 16(2), 161-171.

Giraud, F., Langevin, P., \& Mendoza, C. (2008). Justice as a rationale for the controllability principle: A study of managers' opinions. Management Accounting Research, 19(1), 3244.

Fazio, R. H., \& Zanna, M. P. (1978). Attitudinal qualities relating to the strength of the attitude-behavior relationship. Journal of Experimental Social Psychology, 14(4), 398408.

Flamholtz, E. (1996). Effective organizational control: a framework, applications, and implications. European Management Journal, 14(6), 596-611.

Florentino, M. S., \& Gomes, J. S. (2009). Controle Gerencial em Empresas Brasileiras Internacionalizadas do Setor de Serviços - O caso da Spoleto. Revista Contabilidade, Gestão e Governança, 12(2), 53-74.

Fornell, C., \& Larcker, D. F. (1981). Evaluating structural equation models with unobservable variables and measurement error. Journal of marketing research, (18), 39-50.

Gil, A. C. (2002). Como elaborar projetos de pesquisa. São Paulo, SP: Atlas.

Gil, A. C. (2009). Métodos e técnicas de pesquisa social. São Paulo, SP: Atlas.

Gomes, J. S. \& Amat, J. M. (1999). Controle de gestão: uma abordagem contextual e organizacional. São Paulo, SP: Atlas.

Gomes, J. S., \& Salas, J. M. (2001). Controle de gestão: uma abordagem contextual e organizacional. São Paulo, SP: Atlas. 
Hair, J. F., Hult, T. M., Ringle, C. M., \& Sarstedt, M. (2014). A Primer on Partial Least Squares Structural Equation Modeling (PLS-SEM). Los Angeles, LA: SAGE.

Hoppe, A., Barcellos, M. D. de., Vieira, L. M., \& Matos, C. A. (2012). Comportamento do consumidor de produtos orgânicos: uma aplicação da teoria do comportamento planejado. Revista Base (Administração e Contabilidade) da UNISINOS, 9(2), 15-22.

Huffman, C., \& Cain, L. B. (2000). Effects of considering uncontrollable factors in sales force performance evaluation. Psychology \& Marketing, 17(9), 799-833.

IMA. (2014). Values and Ethics: from inception to practice. Montvale, NJ: IMA.

Jaccard, J. J., \& Davidson, A. R. (1972). Toward an Understanding of Family Planning Behaviors: An Initial Investigation 1. Journal of Applied Social Psychology, 2(3), 228235.

Lakatos, E. M. \& Marconi, M. D. A. (2000). Metodologia científica, 3. ed. São Paulo: Atlas. Langevin, P., \& Mendoza, C. (2013). How can management control system fairness reduce managers' unethical behaviours?. European Management Journal, 31(3), 209-222.

Lima, V. M. L. M., \& D'Amorim, M. A. (1986). A relação atitude-comportamento à luz da Teoria da Ação Racional. Arquivos Brasileiros de Psicologia, 38(1), 133-142.

Loch, K. D., \& Conger, S. (1996). Evaluating ethical decision making and computer use. Communications of the ACM, 39(7), 74-83.

Locke, E. A., Mento, A. J., \& Katcher, B. L. (1978). The interaction of ability and motivation in performance: an exploration of the meaning of moderators. Personnel Psychology,31(2), 269-280.

Lucena, E. R. F. da C. V., Melo, C. L., Lustosa, P. R. B., \& Silva, C. A. T. (2015). Ética: a tendência de os profissionais contábeis denunciarem atos questionáveis. Revista de Contabilidade e Organizações, 9(24), 72-79.

Malhotra, N. (2006). Pesquisa de marketing: uma orientação aplicada. Porto Alegre, RS: Bookman.

Mattar, F. N. (2007). Pesquisa de Marketing. São Paulo, SP: Atlas.

Maroco, J., \& Garcia-Marques, T. (2006). Qual a fiabilidade do alfa de Cronbach? Questões antigas e soluções modernas?. Laboratório de psicologia, 2, 65-90.

Martins, E. C. B., Serralvo, F. A., \& do Nascimento J, B. (2014). Teoria do Comportamento Planejado: Uma aplicação no mercado educacional superior. Gestão \& Regionalidade, 30(88), 101-115.

McNally, G. M. (1980). Responsibility accounting and organisational control: some perspectives and prospects. Journal of Business Finance \& Accounting, 7(2), 165-181.

Merchant, K. A. (1987). How and why firms disregard the controllability principle. Accounting and management: Field study perspectives, (2), 316-338.

Merchant, K. A., \& Van der Stede, W. A. (2007). Management control systems: performance measurement, evaluation and incentives. New York, MH: Pearson Education.

Moreira, J. M. (1996). Ética, economia e política. Porto, PO: Lello \& Irmãos Editores.

Moutinho, K., \& Roazzi, A. (2010). As teorias da ação racional e da ação planejada: relações entre intenções e comportamentos. Avaliação Psicológica, 9(2), 1-10.

Nunnally, J. C., \& Bernstein, I. H. (1994). The theory of measurement error. Psychometric theory, 3, 209-247.

Oyadomari, J. C. T., Cardoso, R. L., Silva, B. O. T. da, \& Perez, G. (2010). Sistemas de controle gerencial: estudo de caso comparativo em empresas inovadoras no Brasil. Revista Universo Contábil, 6(4), 10-15.

Pasquali, K. da S., \& Dal Vesco, D. G. (2016). Responsabilidade civil do Contador: estudo sob 
enfoque do novo Código Civil de 2002 na perspectiva da ética profissional. Contabilidade, Gestão e Governança, 19(2), 292-316.

Pearson, E. S. (1939). "Student" as Statistician. Biometrika, 30(3/4), 210-250.

Pinto, L. J. S., Falcão, D. F., \& Lustosa, P. R. B. (2013). Apuração de fatores não-controláveis: um estudo sobre as ações da empresa Rubi Engenharia em prol da redução dos efeitos negativos. Revista Reunir, 3(2), 107-123.

Pletsch, C. S., Lavarda, C. E. F. \& Lavarda, R. A. B. (2016). Sistema de controle gerencial e sua contribuição para o equilíbrio das tensões dinâmicas. Enfoque, 35(3), 69.

Rezende Pinto, M. de. (2010). A Teoria do Comportamento Planejado (TCP) e o Índice de Disposição de Adoção de Produtos e Serviços Baseados em Tecnologia (TRI): Uma Interface Possível?. Revista Gestão \& Tecnologia, 7(2), 115-126.

Ringle, C. M., Silva, D. da, \& Bido, D. D. S. (2014). Modelagem de equações estruturais com utilização do SmartPLS. Revista Brasileira de Marketing, 13(2), 56-73.

Robertson, D. C., \& Anderson, E. (1993). Control system and task environment effects on ethical judgment: An exploratory study of industrial salespeople. Organization Science, $4(4), 617-644$

Rocha, F. E. de C., de Albuquerque, F. J. B., Marcelino, M. Q., \& Dias, M. R. (2008). Aplicações da Teoria da Ação Planejada: uma possibilidade para estudos comportamentais com agricultores familiares. Planaltina, DF: EMBRAPA Cerrados.

Rosenberg, M. J. (1956). Cognitive structure and attitudinal affect. The Journal of abnormal and social psychology, 53(3), 367.

Schifter, D. E., \& Ajzen, I. (1985). Intention, perceived control, and weight loss: an application of the theory of planned behavior. Journal of personality and Social Psychology, 49(3), 843.

Sheppard, B. H., Hartwick, J., \& Warshaw, P. R. (1988). The theory of reasoned action: A meta-analysis of past research with recommendations for modifications and future research. Journal of consumer research, 15(3), 325-343.

Silva, M. R. (2012). Improbidade administrativa-Instrumentos para o controle preventivo. Fórum Administrativo - FA, 12(139), p. 46-55.

Silva, M. E. da, \& Melo, R. D. C. B. (2012). Os Reflexos de Práticas Socioambientais Organizacionais Sobre as Atitudes Individuais: uma Compreensão à Luz da Teoria do Comportamento Planejado. Revista Capital Científico-Eletrônica (RCCe), 10(1) 1-17.

Simons, R. (2005). Levers of organization design: How managers use accountability systems for greater performance and commitment. Cambridge, MA: Harvard Business Press.

Soares, E. (2003). Metodologia científica: lógica, epistemologia e normas. São Paulo, SP: Atlas.

Terry, D. J., \& O'Leary, J. E. (1995). The theory of planned behaviour: The effects of perceived behavioural control and self-efficacy. British journal of social psychology, 34(2), 199220.

Theodorson, G. A., \& Theodorson, A. G. (1970). A modern dictionary of sociology. London, UK: Methuen.

Tilley, E. (2010). Ethics and gender at the point of decision-making: An exploration of intervention and kinship. Prism, 7(4), 1-19.

Treviño, L. K., Weaver, G. R., \& Reynolds, S. J. (2006). Behavioral ethics in organizations: A review. Journal of Management, 32(6), 951-990.

Triandis, H. C. (1979). Values, attitudes, and interpersonal behavior. Nebraska, MU: University of Nebraska Press. 
Victor, B., \& Cullen, J. B. (1988). The organizational bases of ethical work climates. Administrative science quarterly, (2), 101-125.

Wimbush, J. C., Shepard, J. M., \& Markham, S. E. (1997). An empirical examination of the relationship between ethical climate and ethical behavior from multiple levels of analysis. Journal of Business Ethics, 16(16), 1705-1716. 